\title{
Leptin and the brain: then and now
}

\author{
Michael W. Schwartz', ${ }^{1,2}$ and Denis G. Baskin ${ }^{1,3}$
}

\begin{abstract}
1Division of Metabolism, Endocrinology and Nutrition and 2Diabetes and Obesity Center of Excellence, Department of Medicine, University of Washington,
\end{abstract} Seattle, Washington, USA. ${ }^{3}$ Research and Development Service, Department of Veterans Affairs Puget Sound Health Care System, Seattle, Washington, USA.

\begin{abstract}
The discovery of the adipocyte hormone leptin and the demonstration that severe obesity in $o b / o b$ and $d b / d b$ mice results from mutation of genes encoding leptin and its receptor, respectively, ushered in a new era of obesity research. Our investigation into mechanisms mediating CNS actions of insulin led us to ask whether the two hormones act on a common set of hypothalamic targets. Our finding that this is indeed the case prompted studies that continue to this day. While substantial progress has been made in understanding brain mechanisms of leptin action, translating this knowledge into more effective treatment of obesity remains an elusive goal.
\end{abstract}

In hindsight, our group seemed to be in the right place at the right time when the discovery of leptin ushered in a new era of scientific inquiry in 1994 (1). Beginning in the 1970s with the work of Dan Porte and Steve Woods at the University of Washington and the Seattle VA Medical Center (2), our group had for many years been focused on homeostatic control of body weight and body fat stores (a process subsequently termed "energy homeostasis"). Contrary to mainstream thought at the time, Woods and Porte were convinced that body fat stores are subject to homeostatic regulation, and they advanced the idea that the hormone insulin functions as a feedback signal in this control system $(2,3)$. This concept was founded on three well-established observations: plasma insulin levels vary in proportion to body fat mass (adiposity) (4), insulin receptors are concentrated in hypothalamic regions involved in energy balance (5), and CNS administration of insulin reduces food intake and body weight (2). Porte and Woods hypothesized that rising insulin levels that accompany increased adiposity provide a signal to the brain, limiting weight gain by activating CNS circuits that reduce food intake and increase energy expenditure. Conversely, lowered circulating insulin levels resulting from weight loss (e.g., reduced adiposity) were proposed to activate brain responses that stimulate feeding and promote recovery of depleted body fat stores. A major unanswered question at the time was, "Where are the neuronal targets located -

Conflict of interest: Michael W. Schwartz has served as a consultant for Pfizer Inc. and receives research support from Novo Nordisk A/S.

Citation for this article: J Clin Invest. 2013; 123(6):2344-2345. doi:10.1172/JCI69346. and what is their cellular phenotype - that mediate these energy homeostatic effects of insulin?" In a very real sense, the work that led to answers to these questions established a paradigm for the almost immediate acceptance by the scientific community of the idea that leptin also exerts its effects on energy homeostasis by acting in the CNS.

In a parallel line of inquiry, Doug Coleman had used parabiosis, a method whereby two animals share a single, surgically connected circulatory system, to determine whether obesity or leanness can be transferred between animals by a humoral signal. By applying this method to genetically obese $o b / o b$ and $d b / d b$ mice, Coleman concluded that the former mice lack a humoral signal required for energy homeostasis, whereas the latter are resistant to the same signal (6). This proved to be a remarkably prescient prediction, confirmed in 1994 by the positional cloning of the $o b$ gene locus (1) and discovery of leptin by Jeff Friedman in collaboration with Rudy Libel and Jules Hirsch at The Rockefeller University. The findings that the $o b$ locus encodes leptin (1) and the $d b$ locus encodes the leptin receptor (7) and that loss-of-function mutation of either gene causes severe obesity (in $o b / o b$ and $d b / d b$ mice, respectively) raised a series of fundamental questions for the field to address: "How does leptin regulate energy balance? Does defective leptin action contribute to obesity? Can human obesity be treated effectively with leptin?" The observation that circulating leptin levels are elevated in obese humans suggested that obesity might be associated with leptin resistance, just as it is with insulin resistance. This possibility heightened the need to understand how leptin works and whether leptin action is dysfunctional in obese individuals.
It is against this backdrop that our group, which in the mid-1990s included Randy Seeley (then a postdoc with Steve Woods), expanded our focus to identify neuronal targets of leptin as well as insulin action. We focused initially on neurons in the hypothalamic arcuate nucleus that contain neuropeptide Y (NPY), a peptide that potently stimulates feeding when administered into the brain (8). Since fasting activates this neuronal subset (as judged by increased Npy gene expression) (9), arcuate nucleus NPY neurons were proposed to contribute to the effect of fasting to stimulate food intake. In 1992, we reported that the ability of fasting to induce hypothalamic Npy gene expression is blocked by central insulin administration $(10,11)$, suggesting that fasting-induced activation of NPY neurons arises in part from a reduced insulin signal. Stated differently, we surmised that insulin reduces food intake, in part by inhibiting NPY neurons, and that the effect of fasting to reduce circulating insulin levels is a trigger that activates NPY neurons and thereby stimulates feeding behavior.

This view of how insulin might attenuate feeding by inhibiting hypothalamic NPY neurons provided a heuristic model for subsequent studies designed to determine the mechanism of leptin's effects on food intake. Although leptin is expressed in adipose tissue while insulin is secreted from pancreatic islets, both hormones circulate at levels proportionate to body fat stores and each reduces food intake following CNS administration. It was therefore logical for us to ask whether some of the hypothalamic targets that respond to insulin might be sensitive to leptin as well, and this prediction proved to be accurate. Thus, in our 1996 JCI paper (12), we showed that leptin receptors (like insulin receptors) are concentrated in the hypothalamic arcuate nucleus and that, when administered into the brains of fasted rats, leptin (like insulin) inhibits Npy gene expression in this brain area. Our focus on central mechanisms of insulin action had therefore positioned us well to interrogate leptin action in the hypothalamus, as the two hormones proved to share some of the same neuronal targets. 
Not surprisingly, our early observations raised more questions than they answered. Some of these have proven to be more challenging than we had imagined and remain unanswered to this day. Although steady progress has been made in mapping "energy balance neurocircuits" and clarifying how this network regulates feeding behavior, the field is complex and still in its infancy (13). The list of relevant humoral inputs to these circuits besides insulin and leptin also remains incomplete, as does our understanding of how hypothalamic responses to adiposity-related inputs, such as leptin and insulin, are linked to the control of feeding behavior by mealrelated, short-acting satiety signals like cholecystokinin (14) on the one hand and to the rewarding properties of highly palatable foods on the other (15). The key intracellular signal transduction pathways that mediate neuronal actions of leptin and insulin have largely been worked out (16), but how they regulate neuronal firing and synaptic plasticity awaits additional study. Even more challenging are the questions of how these collective insights relate to the pathogenesis of leptin resistance and whether leptin resistance is a cause or a consequence of obesity (17).

At the time of our 1996 JCI paper, it was quite exciting to see answers to these questions begin to emerge, and we were hopeful that they would quickly translate into new therapies for obesity - so hopeful, in fact, that one of us launched a Weight Disorders Clinic in 1998 at Harborview Medical Center in Seattle. The goal of this clinic was to provide a local clinical infrastructure with which to meet the anticipated need for expertise created by the new antiobesity therapeutics that we expected would soon hit the market. It is with a very real sense of disappointment that we acknowledge that this expectation remains unmet some 15 years later. In retrospect, the dramatic advances in our understanding of the role of leptin in energy homeostasis have not produced correspondingly beneficial therapeutic improvements in the treatment of obesity. Lying at the heart of this failure is the fundamental but often overlooked fact that obesity does not arise from passive accumulation of excess body fat, but rather involves the homeostatic defense of an elevated level of body adiposity (18). Because mechanisms underlying energy homeostasis are highly integrated and redundant, drugs targeting a single component of the system activate compensatory responses elsewhere that resist further weight loss and favor the eventual return to baseline weight. Consequently, effective obesity treatment will likely require drug combinations that induce weight loss while also blocking the associated adaptive responses. Indeed, leptin is one of the few molecules known to exert both types of effects, but obesity-associated leptin resistance limits its therapeutic potential. Without an improved understanding of the causes and consequences of this leptin resistance, therapeutic breakthroughs may continue to prove elusive.

A key question, therefore, is whether defective hypothalamic leptin signaling plays a causal role in the biological defense of elevated body fat content. If so, and if the cause of this impairment were understood in molecular and physiological terms, new opportunities for intervention might emerge. One possibility is that leptin resistance and obesity pathogenesis both arise from inflammation, gliosis, and injury of neurons in the arcuate nucleus, a possibility advanced in a recent JCI paper from our group (19). Our findings support a model in which "fixed structural change" affecting energy balance neurocircuits contributes to the defense of an elevated level of body fat mass in obese individuals, even after they adopt "healthy" diets and lifestyles that no longer perpetuate the CNS injury process. We are hopeful that we will one day see, in hindsight, that this hypothesis has proven useful in unraveling the causes of CNS leptin resistance and that continued progress in our understanding of obesity pathogenesis will lead to breakthroughs that reverse its devastating toll on human health.

\section{Acknowledgments}

This work was supported by the National Institute of Diabetes and Digestive and Kidney Diseases (grant nos. DK068384, DK083042, DK090320, and DK052989); the Nutrition Obesity Research Center (no. DK035816); and the Diabetes Research Center (no. P30 DK17047) at the University of Washington. It is also based on work supported by the Office of Research and Development, Medical Research Service, Department of Veterans Affairs. D.G. Baskin is the recipient of a Department of Veterans Affairs Senior Research Career Scientist Award at the VA Puget Sound Health Care System.

Address correspondence to: Michael W. Schwartz, Department of Medicine, Uni- versity of Washington at South Lake Union, 850 Republican St., N334, Box 358055, Seattle, Washington 98195, USA. Phone: 206.897.5288; Fax: 206.897.5293; E-mail: mschwart@u.washington.edu.

1. Zhang Y, Proenca R, Maffei M, Barone M, Leopold L, Friedman JM. Positional cloning of the mouse obese gene and its human homologue. Nature. 1994; 372(6505):425-432.

2. Woods SC, Lotter EC, McKay LD, Porte D Jr. Chronic intracerebroventricular infusion of insulin reduces food intake and body weight of baboons. Nature. 1979;282(5738):503-505.

3. Woods SC, et al. Insulin: its relationship to the central nervous system and to the control of food intake and body weight. Am J Clin Nutr. 1985; 42(5 suppl):1063-1071.

4. Bagdade JD, Bierman EL, Porte D Jr. The significance of basal insulin levels in the evaluation of the insulin response to glucose in diabetic and nondiabetic subjects. J Clin Invest. 1967; 46(10):1549-1557.

5. Marks JL, Porte D Jr, Stahl WL, Baskin DG. Localization of insulin receptor $\mathrm{mRNA}$ in rat brain by in situ hybridization. Endocrinology. 1990; 127(6):3234-3236.

6. Coleman DL. Effects of parabiosis of obese with diabetes and normal mice. Diabetologia. 1973; 9(4):294-298

7. Tartaglia LA, et al. Identification and expression cloning of a leptin receptor, OB-R. Cell. 1995; 83(7):1263-1271.

8. Clark JT, Kalra PS, Kalra SP. Neuropeptide Y stimulates feeding but inhibits sexual behavior in rats. Endocrinology. 1985;117(6):2435-2442.

9. Sanacora G, Kershaw M, Finkelstein JA, White JD. Increased hypothalamic content of preproneuropeptide $Y$ messenger ribonucleic acid in genetically obese Zucker rats and its regulation by food deprivation. Endocrinology. 1990;127(2):730-737.

10. Schwartz MW, et al. Inhibition of hypothalamic neuropeptide $Y$ gene expression by insulin. Endocrinology. 1992;130(6):3608-3616.

11. Schwartz MW, Figlewicz DP, Baskin DG, Woods SC, Porte D Jr. Insulin in the brain: a hormonal regulator of energy balance. Endocr Rev. 1992; 13(3):387-414.

12. Schwartz MW, Seeley RJ, Campfield LA, Burn $\mathrm{P}$, Baskin DG. Identification of targets of leptin action in rat hypothalamus. J Clin Invest. 1996; 98(5):1101-1106.

13. Williams KW, Elmquist JK. From neuroanatomy to behavior: central integration of peripheral signals regulating feeding behavior. Nat Neurosci. 2012; 15(10):1350-1355.

14. Grill HJ, Kaplan JM. The neuroanatomical axis for control of energy balance. Front Neuroendocrinol. 2002;23(1):2-40.

15. Figlewicz DP. Adiposity signals and food reward: expanding the CNS roles of insulin and leptin. Am J Physiol Regul Integr Comp Physiol. 2003; 284(4):R882-R892.

16. Myers MG Jr. Leptin receptor signaling and the regulation of mammalian physiology. Recent Prog Horm Res. 2004;59:287-304.

17. Myers MG Jr, Leibel RL, Seeley RJ, Schwartz MW. Obesity and leptin resistance: distinguishing cause from effect. Trends Endocrinol Metab. 2010; 21(11):643-651.

18. Ryan KK, Woods SC, Seeley RJ. Central nervous system mechanisms linking the consumption of palatable high-fat diets to the defense of greater adiposity. Cell Metab. 2012;15(2):137-149.

19. Thaler JP, et al. Obesity is associated with hypothalamic injury in rodents and humans. J Clin Invest. 2012;122(1):153-162. 